특집논문-10-15-6-09

$$
\begin{gathered}
\text { 콘텐츠 기반 움직임 적응형 디인터레이싱 기법 } \\
\text { 김 민 환 }{ }^{a)} \text { 이 창 우), 이 성 원(a) }
\end{gathered}
$$

\title{
A Content-Based Motion Adaptive DeInterlacing Technique
}

\author{
Min-Hwan Kim ${ }^{\text {a) }}$, Chang-Woo Lee ${ }^{\text {b) }}$, and Seong-Won Lee ${ }^{\text {a) }}$ \\ 요 약
}

최근 LCD TV와 같은 순차 주사형 디스플레이의 보급에 따라 HDTV등의 전송에 사용된 비월 주사 영상을 순차 주사 영상으로 변 환하는 기존의 디인터레이싱 기술에 대한 화질 개선 요구가 커지고 있다. 본 논문에서는 영상 콘텐츠에 따른 움직임 정보의 통계값을 계산하여 영상 콘텐츠의 종류별로 미리 설정된 임계값에 따라 공간적, 시간적 디인터레이싱 방법을 선택적으로 적용하는 움직임 적응 형 디인터레이싱 기법을 제안한다. 또한 공간적 디인터레이싱의 화질을 개선하기 위하여 소벨 연산을 이용하여 수직 에지와 수평 에지 의 비율에 따라 M-ELA 방법과 DOI 방법을 선택적으로 사용하는 개선된 공간적 디인터레이싱 방법을 제안한다. 다양한 실험 영상에 대한 객관적, 주관적 평가를 통하여 제안한 방법이 기존의 디인터레이싱 방법에 비해 우수한 화질을 보임을 확인하였다.

\begin{abstract}
Recent prevalence of progressive scan display such as LCD TV demands the quality improvement of existing deinterlacing techniques that convert interlaced scan images including HDTV broadcasting to progressive scan images. In this paper, we propose a motion adaptive deinterlacing technique which can be used for spatial methods, temporal methods, and the spatial-temporal methods can be used for the deinterlacing techniques selectively based on the threshold values calculated by the statistics of motion in the video contents. We also propose an improved spatial deinterlacing technique that adaptively use M-ELA and DOI based on the slant of edges that are obtained by Sobel operation. The improved picture quality of the proposed algorithm is confirmed by objective and subjective quality tests on many test image sequences.
\end{abstract}

Keywords : DOI, ELA, Motion Adaptive Deinterlacing, Content-based method

\section{I. 서 론}

a) 광운대학교 컴퓨터공학과

Dept. of Computer Engineering, Kwangwoon University

b) 가톨릭대학교 정보통신전자공학부

Dept. of Information Communications and Electronics Eng., The Catholic University of Korea

\# 교신저자 : 이성원(swlee@kw.ac.kr)

※ 본 논문은 교육과학기술부의 재원으로 한국연구재단(2010-0028178, 2010-0015441)및 지식경제부가 지원하는 국가 반도체 연구개발사업인 시스템 직접 반도체 기반 기술 개발 사업(SystemIC-2010)의 지원에 의해 연구되었음

- 접수일(2010년8월30일),수정일(2010년11월5일),게재확정일(2010년11 월26일) 
하기 위하여 비월 주사 방식을 순차 주사 방식으로의 변환 하는 디인터레이싱(Deinterlacing)방법이 많이 연구되고 있 다 $^{[1 \sim 5]}$.

디인터레이싱 방법은 움직임 보상(Motion Compensation)방법과 움직임 보상을 하지 않는 (Non-Motion Compensation)방법으로 구분 할 수 있다. 움직임 보상 방법은 움직임 예측(Motion Estimation)을 통하여 이전 필드의 움 직임 이전 영상을 사용하여 보간 하는 방법으로 계산량이 많아 복잡도가 높아짐으로 인하여 하드웨어로 구현 시 가 격이 올라가게 되며, 움직임 예측이 틀렸을 경우 잘못된 보 정으로 심각한 화질의 열화가 발생하게 된다 ${ }^{[12]}$.

움직임 보상을 하지 않는 방법으로는 시간적 디인터레 이싱(Temporal Deinterlacing)방법, 공간적 디인터레이싱 (Spatial Deinterlacing)방법 그리고, 시간적, 공간적 디인 터레이싱을 혼합하는 형태인 움직임 적응형 디인터레이 싱이 있다 ${ }^{[2]}$. 움직임 적응형 디인터레이싱에서는 영상의 정확한 움직임의 유, 무가 중요하기 때문에 움직임 검출 (Motion Detection)과정을 거치게 된다. 최신의 디인터레 이싱 방법으로는 퍼지이론을 디인터레이싱에 적용한 방 법이 Jeon's의 의하여 연구가 진행되고 있다 ${ }^{[10-11]}$. 퍼지를 이용한 방법은 컴퓨팅 관련 분야에서 많이 진행되고 있 다. 퍼지이론은 연산량이 많아 하드웨어로 구현하기에 적 합하지 않다.

시간적 디인터레이싱의 대표적인 방법으로는 필드 반복 (Field Repetition)방법이 대표적이다. 필드 반복 방법은 비 월 영상의 홀수필드와 짝수필드를 직접 합하는 방법으로 정지 영상에서는 우수한 성능을 보이나 움직임이 발생하 는 영상에서는 심각한 화질의 열화를 발생하게 되는 단점 이 있다 ${ }^{[2]}$. 대표적인 공간적 디인터레이싱 방법으로는 선 평균(Line Average) 방법이 있다. 선 평균 방법은 보간 할 화소의 상, 하의 화소값의 평균으로 보간 하여 계산량이 적지만 에지 성분이 강한 영상에서는 심한 화질의 열화가 발생한다. 따라서 선 평균 방법을 보완한 ELA(Edge based Line Average), E-ELA(Chen Filter), M-ELA(Kim's Filter) 와 같은 방법이 소개되었다 ${ }^{[3,6-9]}$. ELA 계열의 디인터레이 싱 방법은 45 도 보다 큰 수직 성분이 많은 영상에서는 우 수한 성능을 보이나 45 도 보다 낮은 각이 많은 영상에서는
우수한 성능을 보이지 못한다. ELA계열의 단점을 해결한 방법이 DOI(Direction-Oriented Interpolation)방법이다 ${ }^{[4]}$. $\mathrm{DOI}$ 방법은 수평 성분의 강한 에지 성분이 많은 영상에서 우수한 성능을 보이지만 일반적인 공간적 디인터레이싱 방법에 비하여 계산량이 많고 복잡도가 높은 영상에서는 다른 공간적 디인터레이싱 방법과 마찬가지로 공간 방향 벡터를 잘못 찾아 보간 하여 화질의 심각한 열화가 발생하 기도 한다.

본 논문에서는 이러한 기존의 공간적 디인터레이싱, 시 간적 디인터레이싱의 문제점을 개선한 콘텐츠 기반 움직임 적응형 디인터레이싱 기법을 제안하였다. 움직임 적응형 디인터레이싱에서 가장 중요한 움직임 검출을 정확히 하기 위하여 블록 기반 5 필드 움직임 검출(Block-based Five Field Motion Detection)을 제안하였다. 또한 움직임 검출에 서의 정도값을 가지고 영상의 유형을 움직임이 전체에 있 는 영상, 움직임이 부분적으로 큰 영상, 움직임이 적은 영상 3 가지로 구분을 하여 공간적, 움직임 적응형, 시간적 디인 터레이싱을 각각 적용한다. 또한 제안된 방법의 공간적 디 인터레이싱에서는 정확한 에지 검출을 위하여 소벨 연산을 이용한 비월 영상의 에지 성분을 찾아낸다. 이렇게 찾아진 에지의 기울기에 따라 M-ELA 방법과 M-DOI(Modified Direction-Oriented Interpolation)방법을 적응적으로 사용 하였다.

본 논문의 II장에서는 기존의 디인터레이싱 기법을 소개 하고, III장에서는 제안하는 기법을 설명한다. IV장에서는 실험 결과 및 고찰에서 여러 영상을 통하여 제안된 기법의 성능을 검증하고, $\mathrm{V}$ 장에서는 본 논문의 결론을 맺는다.

\section{II. 기존의 디인터레이싱 기법}

M-ELA 방법은 ELA와 E-ELA 방법에서 발생할 수 있는 잘못된 방향 결정을 보다 줄이기 위하여 E-ELA 방법은 방 향성 측정 방법인 $\mathrm{P}$ 와 $\mathrm{Q}$ 식에서 $\mathrm{V}$ 의 방향성 예측을 추가 하여 수직 성분의 강한 에지가 많은 영상에서 우수한 성 능을 보이는 방법이다. $\mathrm{P}$ 와 $\mathrm{Q}, \mathrm{V}$ 의 측정 단위는 다음 그 림 1에 나타난 방향성에 따라 식 (1)에 의해 계산된다 ${ }^{[6[8-9]}$. 


$$
\begin{aligned}
P & =(|U(i-1)-L(i)|+|U(i)-L(i+1)|) / 2 \\
Q & =(|U(i)-L(i+1)|+|U(i+1)-L(i)|) / 2 \\
V & =(|U(i-1)-L(i-1)|+|U(i)-L(i)|+|U(i+1)-L(i+1)|) / 3 \\
S_{U}(k) & =\sum_{j=-1}^{1}\left(\left|U_{0}(i+j)-U_{1}(i+j+k)\right|^{2}+\left|L_{0}(i+j)-U_{0}(i+j+k)\right|^{2}\right) \\
S_{L}(k) & =\sum_{j=-1}^{1}\left(\left|U_{0}(i+j)-L_{0}(i+j+k)\right|^{2}+\left|L_{0}(i+j)-L_{1}(i+j+k)\right|^{2}\right) \\
s d v_{U} & =\operatorname{argmin} S_{U}(k),-R \leq k \leq R \\
s d v_{L} & =\operatorname{argmin} S_{L}(k),-R \leq k \leq R, R= \pm 16 \\
X(i) & =\frac{U_{0}\left(i+\left(s d v_{U} / 2\right)\right)+L_{0}\left(i+\left(s d v_{L} / 2\right)\right)}{2}
\end{aligned}
$$

$\mathbf{P}$

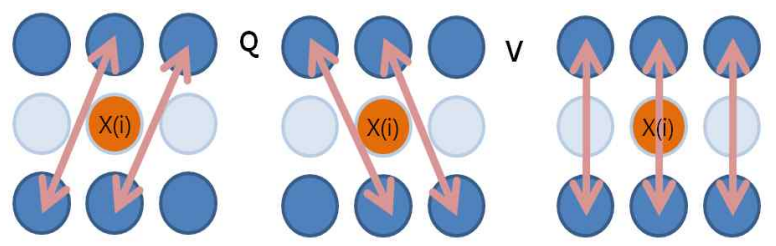

그림 1. M-ELA 방향성 측정 단위

Fig. 1. Illustration of the M-ELA directionality unit of measure

M-ELA 방법은 $\mathrm{P}$ 나 $\mathrm{Q}, \mathrm{V}$ 의 방향을 따라 보간 된다.

M-ELA 방법은 계산량이 적고 수직 에지에 좋은 결과를 보이나 수평 에지에 취약한 문제가 있다 ${ }^{[8]}$. 수평 에지에 강 한 DOI 방법은 현재 화소를 보간 하기 위해 2 개의 상단 참 조 라인 $\left(U_{0}, U_{1}\right)$ 과 2개의 하단 참조 라인 $\left(L_{0}, L_{1}\right)$ 을 사용한 다. 참조 라인에서 얻어지는 상위 공간 방향 벡터(upper spatial direction vector, $s d v_{U}$ )와 하위 공간 방향 벡터 (lower spatial direction vector, $s d v_{L}$ )를 이용함으로써 정확 한 에지의 방향을 찾는다 ${ }^{[4]}$. 하지만 복잡도가 높은 영상이 나 수직 에지가 강한 영상에서는 그리 좋은 성능을 보이지 않는다 ${ }^{[6-9]}$. 그림 2에서 $U_{0}$ 과 $U_{1}, L_{0}$ 과 $L_{1}$ 은 각각 상위와 하위의 참조라인을 나타낸다. 방향에 따른 상관성의 강도 를 나타내는 $S_{U}$ 와 $S_{L}$ 를 계산하여 공간 방향 벡터 $s d V_{U}$ 와 $s d v_{L}$ 을 구한다. 공간 방향 벡터들이 구해지고이들이 동일 한 선상에 위치한다면 보간 될 화소의 방향도 정해진다. 최 종 보간 될 $X(i)$ 의 화소값은 식 (2)에 의해 구해 질 수 있다. 필드 반복 디인터레이싱 방법은 이전 영상의 값을 가져오 는 시간적 디인터레이싱의 한 방법이다. 필드 반복은 식 (3)

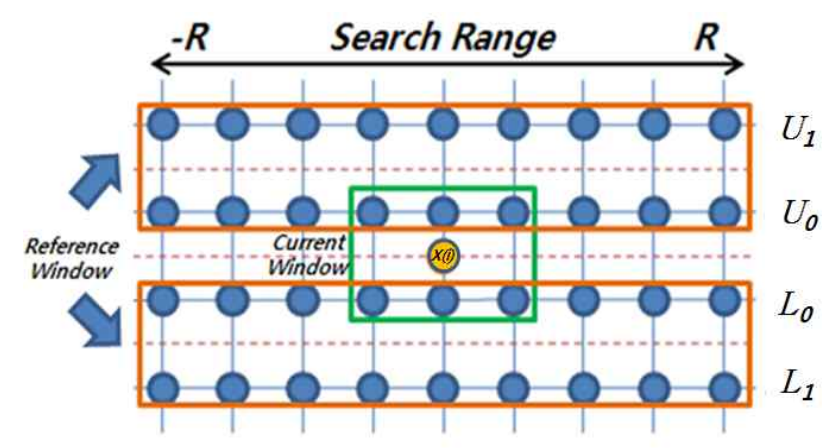

그림 2. $\mathrm{DO}$ 이 알고리즘을 위한 개념도

Fig 2. Illustration of the DOI method

와 같이 표현되며, 가장 단순한 방법이고 움직임에 의한 화질 열화가 심하지만 정지 영상에서는 가장 우수한 화질 을 보인다 ${ }^{[2]}$.

$$
F_{o}(i)=\left\{\begin{array}{l}
F_{n}(i), \bmod (i, 2)=\bmod (n, 2) \\
F_{n-1}(i), \text { otherwise }
\end{array}\right.
$$

이러한 시간적 디인터레이싱 방법과 공간적 디인터레이 싱 방법의 장점을 살리고 단점을 보완하기 위하여 사용하 는 움직임 적응형 디인터레이싱 기법은 시간적, 공간적 디 인터레이싱을 움직임에 따라 적응적으로 사용하는 디인터 레이싱 방법이다 ${ }^{[2]}$. 움직임 검출 부분에서 움직임 검출을 하게 되어 시간적, 공간적 부분에 가중치를 두어 움직임이 많으면 공간적 디인터레이싱에 가중치를 두고 움직임이 적 으면 시간적 디인터레이싱에 가중치를 두어 보간 하는 기 


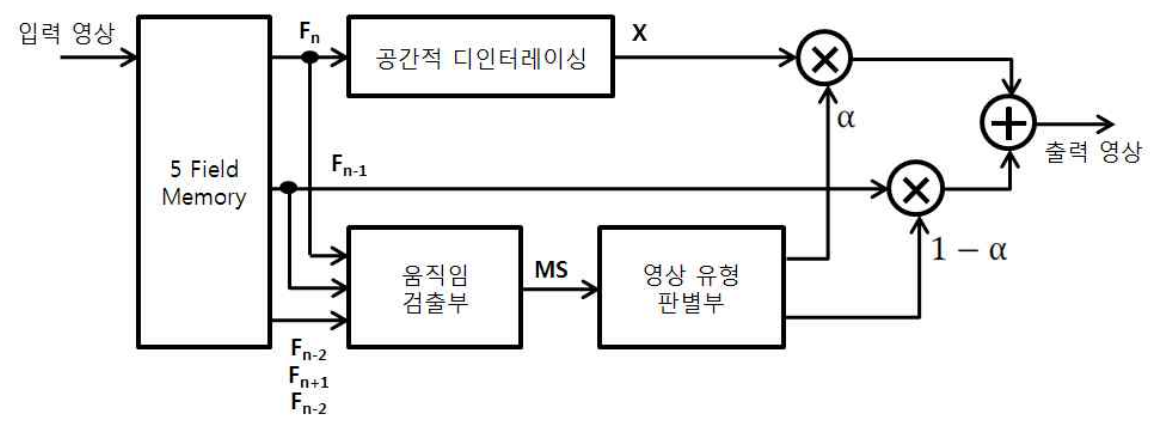

그림 3. 제안하는 디인터레이싱 기법 블록 다이어그램

Fig 3. Block Diagram of the proposed method

법으로 본 논문에서 제안된 콘텐츠 기반 움직임 적응형 디 인터레이싱 기법도 여기에 속한다.

\section{III. 제안하는 디인터레이싱 기법}

제안하는 디인터레이싱 기법은 먼저 움직임 검출부에 서 움직임의 정도값(MS)을 계산을 한다. 움직임 검출부에 서 나온 움직임 정도값을 가지고 영상 유형 판별부에서 영 상의 유형을 3 가지로 판단하여 영상의 유형에 따라 정해진 상위 임계값(TH), 하위 임계값(TL)을 이용하여 시간적 디 인터레이싱 방법, 공간적 디인터레이싱 방법, 그리고 시간 적 방법과 공간적 방법을 같이 사용하는 적응적 디인터레 이싱 방법 중 하나를 적용한다. 영상의 움직임이 많은 경우 는 공간적 디인터레이싱 방법에 의한 보간에 가중치를 두 게 되고 움직임이 적은 영상에는 시간적 디인터레이싱 방 법에 의한 보간에 가중치를 두어 디인터레이싱을 수행한다.
이때 가중치의 조정은 $a$ 를 이용한다.

\section{1. 움직임 검출부}

기존의 움직임 검출은 픽셀 단위로 비교하기 때문에 잡 음의 영항을 받기 쉽고, 움직임 미검출(motion missing)과 거짓 움직임(false motion)이 발생 할 수 있다. 움직임 미검 출은 실제 움직임이 있었지만 움직임으로 판단하지 않는 오류이며, 거짓 움직임은 움직임이 없는 영역을 움직임이 있는 것으로 판단하는 오류이다. 제안하는 움직임 검출 방 법에서는 블록 단위로 움직임을 검출함으로써 잡음의 영향 을 억제하고 중심부에 가중치를 줌으로써 움직임 검출의 정확성이 떨어지는 것을 방지하였다. 먼저 식 (4)에서 필드 간의 차를 보간 할 위치의 상관관계에 따라 식 (5)처럼 화소 중심에서 가까운 화소에 가중치를 높게 설정한 필드간의 차 값인 $\mathrm{M} 1, \mathrm{M} 2, \mathrm{M} 3$ 를 구하게 된다. 식 (6)에서는 $\mathrm{M} 1$, $\mathrm{M} 2, \mathrm{M} 3$ 값 중 가장 크게 나온 값을 사용하게 된다. 본 논문

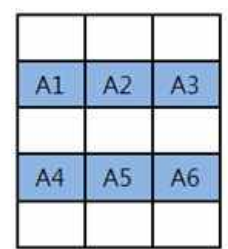

$F_{n-2}$

\begin{tabular}{|l|l|l|}
\hline B1 & B2 & B3 \\
\hline & & \\
\hline B4 & B5 & B6 \\
\hline & & \\
\hline B7 & B8 & B9 \\
\hline
\end{tabular}

$F_{n-1}$

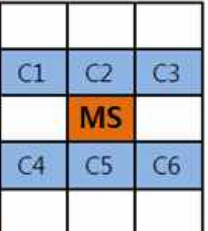

$F_{n}$

\begin{tabular}{|l|l|l|}
\hline D1 & D2 & D3 \\
\hline & & \\
\hline D4 & D5 & D6 \\
\hline & & \\
\hline D7 & D8 & D9 \\
\hline
\end{tabular}

$F_{n+1}$

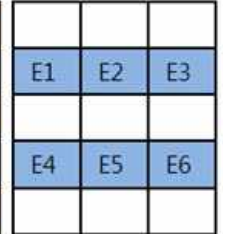

$F_{n+2}$

그림 4. 움직임 검출 블록 다이어그램

Fig 4. Block Diagram of the Motion Detection 
에서는 이와 같이 구해진 움직임 정도값을 MS(Motion Strength)라고 정의하였다.

$$
\begin{aligned}
A C_{i}= & \left|A_{i}-C_{i}\right| \text { for } i=1,2,3,4,5,6 \\
B D_{i}= & \left|B_{i}-D_{i}\right| \text { for } i=1,2,3,4,5,6,7,8,9 \\
C E_{i}= & \left|C_{i}-E_{i}\right| \text { for } i=1,2,3,4,5,6 \\
M 1= & (A C 1+A C 2 * 15+A C 3+ \\
& A C 4+A C 5 * 15+A C 6) / 7 \\
M 2= & (B D 1+B D 2+B D 3+ \\
& B D 4 * 15+B D 5^{*} 2+B D 6^{*} 1.5+ \\
& B D 7+B D 8+B D 9) / 11 \\
M 3= & (C E 1+C E 2 * 15+C E 3+ \\
& C E 4+C E 5 * 1.5+C E 6) / 7 \\
M S= & \max (M 1, M 2, M 3)
\end{aligned}
$$

\section{2. 영상 유형 판별부}

움직임 검출부에서 나온 $\mathrm{MS}$ 값으로부터 영상의 유형을 분류 할 수 있다. 움직임이 많은 경우 $\mathrm{MS}$ 값이 크게 나오는 경향이 있으므로 필드 전체의 $\mathrm{MS}$ 값의 평균을 구하여 영상 의 유형을 판별한다. 영상의 유형은 전체적으로 움직임이 많은 경우 평균값이 높게 나오고, 부분적인 움직임이 큰 영 상의 경우는 평균값이 중간 정도 나오게 된다. 움직임이 적 은 영상의 경우는 평균값이 작게 나온다. 이에 따라 실험적 으로 상위 임계값 $(\mathrm{TH})$ 과 하위 임계값(TL)을 구하여 $\mathrm{MS}$ 값 이 상위 임계값 보다 크면 공간적 디인터레이싱을, 상위 임 계값보다 작고 하위 임계값 보다 크면 $\alpha=\mathrm{MS} / 255$ 를 사용 하여 움직임 적응형 디인터레이싱을 사용한다. 또한 $\mathrm{MS}$ 값
이 하위 임계값 보다 작을 경우는 시간적 디인터레이싱으 로 필드 반복 방법을 사용한다. 움직임 적응형 디인터레이 싱에서 출력 영상값은 식 (7)와 같이 구하였다.

또한 다양한 종류의 영상에 대한 실험을 통하여 $\mathrm{MS}$ 의 평균값이 높은 경우는 상위 임계값은 30 , 하위 임계값은 5 를 적용하며, $\mathrm{MS}$ 의 평균값이 낮은 경우는 상위 임계값은 70 , 하위 임계값은 15 를 적용한다. $\mathrm{MS}$ 의 평균값이 중간정 도이면 상위 임계값은 50 , 하위 임계값은 10 을 사용하였다.

$$
\text { 출력 영상 }=F_{n-1} * \alpha+X *(1-\alpha)
$$

\section{3. 제안하는 공간적 디인터레이싱 방법}

제안하는 공간적 디인터레이싱에서는 소벨 연산자를 사 용하여 에지를 구한 후 에지의 기울기를 측정한다. 에지의 기울기 45 도 보다 클 경우 45 도 이상의 에지 방향에 효율적 인 M-ELA 방법으로 보간 한다. 그리고 기울기가 45 도 보다 작을 경우에는 수평 성분의 에지가 강하므로 수직 에지 검 색을 생략한 M-DOI 방법으로 보간 한다. 제안하는 공간적 디인터레이싱 방법의 블록 다이어그램은 그림 5 와 같다.

소벨 연산을 위하여 Jin's이 제안한 방법을 사용한다 ${ }^{[5]}$. 이때 소벨 연산을 위하여 먼저 M-ELA 방법을 적용하여 비 어있는 화소 부분을 채운 후 연산을 진행한다. Jin's 방법에 서 방향성에 따라서 소벨값이 구해지면 그중 가장 큰 2개의 소벨값을 가지고 각도가 판단된다. 여기서 나온 각도 값을 가지고 에지 판별부에서 에지의 성분이 45 도 보다 큰지 작

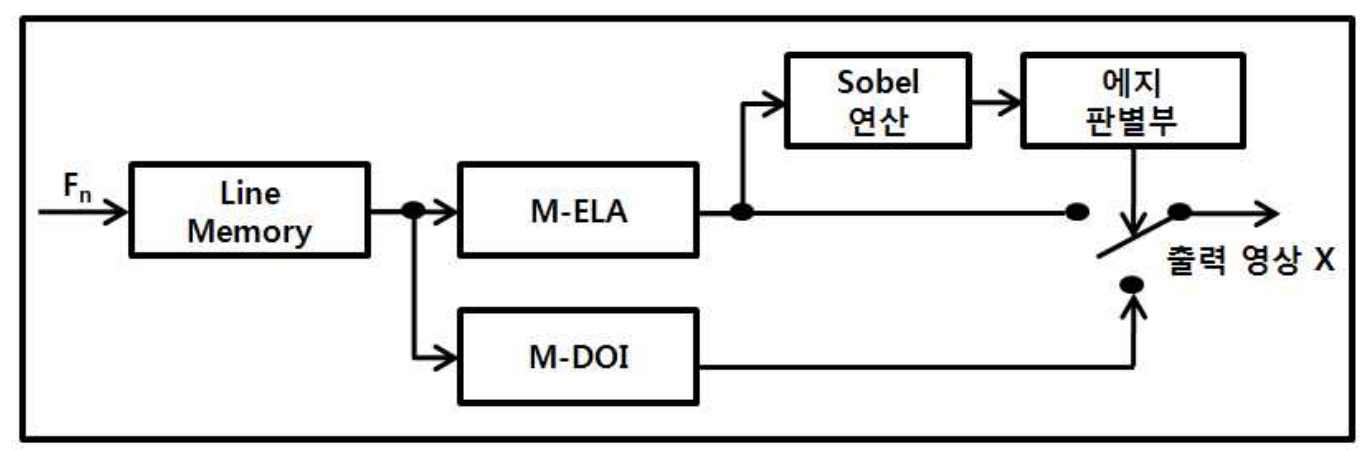

그림 5. 제안하는 공간적 디인터레이싱 방법의 블록 다이어그램

Fig 5. Block Diagram of the proposed spatial deinterlacing method 


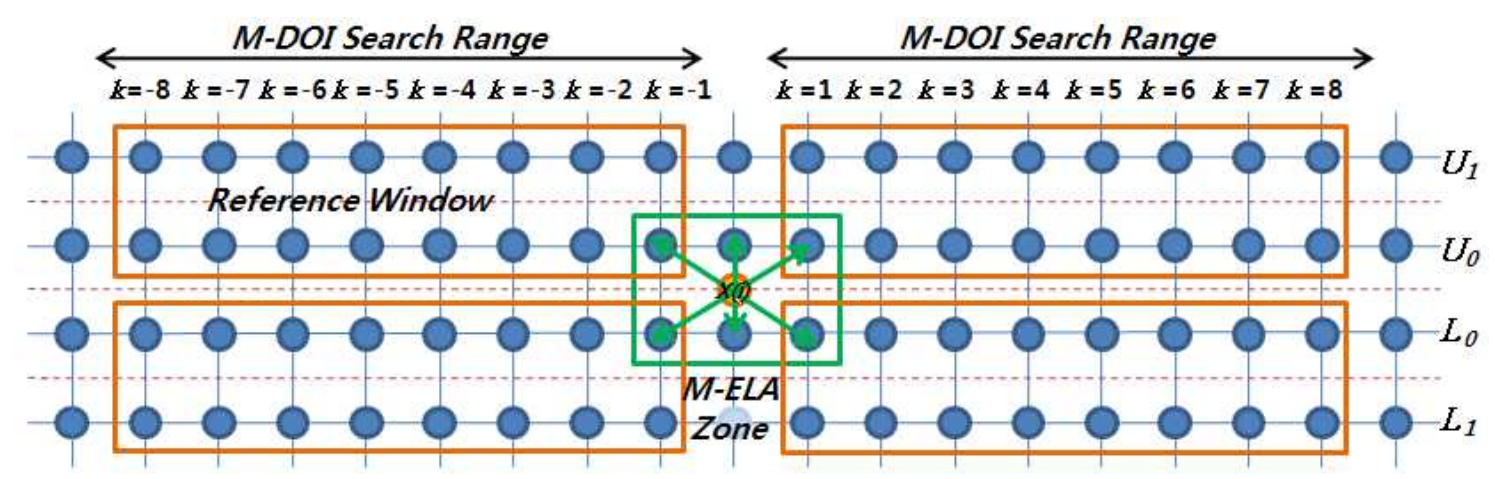

그림 6. M-DOI 방법

Fig 6. Modified DOI method

은지를 판단하여 M-ELA 방법으로 보간 할지 M-DOI 방법 으로 보간 할지 판단하게 된다. 제안하는 디인터레이싱 방 법에서는 45 도 이상의 에지에 대하여 M-ELA 방법을 사용 하므로 DOI 방법의 검색 범위인 화소거리 $\mathrm{k}=0, \mathrm{k}= \pm 1$ 일 경우에는 에지의 기울기가 45도 이상이므로 M-DOI 방법 을 수행하지 않는다. 또한 실험을 통해 탐색 영역의 크기를 8 로 줄여도 성능에 큰 영향이 없음을 확인하여 탐색 영역을 줄였다. 그림 6에서 M-DOI 방법의 탐색 영역과 계산시 비 교되는 화소의 위치를 보여주고 있다. 기존의 DOI 방법은 복잡도가 높은 영상이나 수직 성분이 강한 에지에서 지나 치게 많은 연산이 필요하거나 보간 오류를 발생하는 등 좋 은 성능을 낼 수 없었다다. 제안된 공간적 디인터레이싱에 서는 M-DOI 방법과 함께 수직 에지에 대한 보간은 M-ELA 방법을 같이 사용함으로써 수직 성분이 강한 에지와 검색 범위를 줄이고 선택적으로 보간함으로써 기존의 DOI 방법 의 문제점을 해결하였다.

\section{IV. 실험 결과 및 고찰}

객관적 화질 평가를 위하여 19 가지 $352 \times 288$ 영상을 (Akiyo, Bridge_Far, Bridge_Close, Bus, Container, Coastguard, Flower, Football, Foreman, Hall, Highway, Mobile, Mother, News, Paris, Silent, Stefan, Tempete, Waterfall) $352 \times 144$ 영상으로 Down-Sampling 한 후 디인터레이싱 과정을 $80 \mathrm{Frame}$ 의 디인터레이싱 복원 영상과 원본 영상을
비교하여 PSNR 계산을 하였다. 주관적 화질 평가를 위하 여 $720 \times 240$ 비월 주사 영상 Cross walk 영상을 순차 주사 영상으로 변환하여 평가하였다. 또한 객관적 화질 평가에 사용되었던 Foreman 영상을 주관적 화질 평가에 사용하였 다. 복잡도 계산을 위하여 PSNR 계산에 사용된 19가지 각 영상의 80 Frame의 평균 CPU Time을 구하여 ELA, E-ELA, M-ELA, DOI 그리고 제안된 방법의 CPU Time을 비교하였다.

제안된 디인터레이싱 방법은 영상 유형에 따라 다른 임 계값을 사용하므로 $\mathrm{MS}$ 의 평균값에 따라 영상을 분류하게 된다. Bus 영상일 경우는 움직임이 많은 영상으로 움직임 검출에서의 그림 7에서 보는바와 같이 $\mathrm{MS}$ 값 중 높은 값이 골고루 나오는 것을 확인 할 수 있었다. 그림 8 에서 보는바 와 같이 Foreman 영상일 경우는 움직임 검출에서의 $\mathrm{MS}$ 값 이 크게 나온 부분보다 적게 나온 부분이 Bus 영상보다는 적게 나오는 것을 알 수 있다. 그렇지만 배경영역이 많이 나오는 Akiyo 영상보다는 MS값이 높게 나옴을 알 수 있었 다. 그림 9에서 보는바와 같이 Akiyo 영상처럼 배경영역이 많은 영상은 움직임이 거의 없는 영상으로 움직임 검출에 서 나온 $\mathrm{MS}$ 값이 $\mathrm{MS}<4$ 인 배경영역이 거의 차지하고 $4 \leq$ $\mathrm{MS}<50$ 부분에 일부가 몰려있는 것을 알 수 있다. 그 결과 로 배경이 많은 영상임을 알 수 있었다.

실험에 사용된 19 가지 영상의 $\mathrm{MS}$ 의 평균값에 따라 유형 을 분류하였다. 움직임이 많은 영상 (Group A) Flower, Football, Mobile, Bus, Stefan으로 평균 MS값은 96.9였다. 움직임이 적은 영상들(Group C)은 Akiyo, Mother, News, 


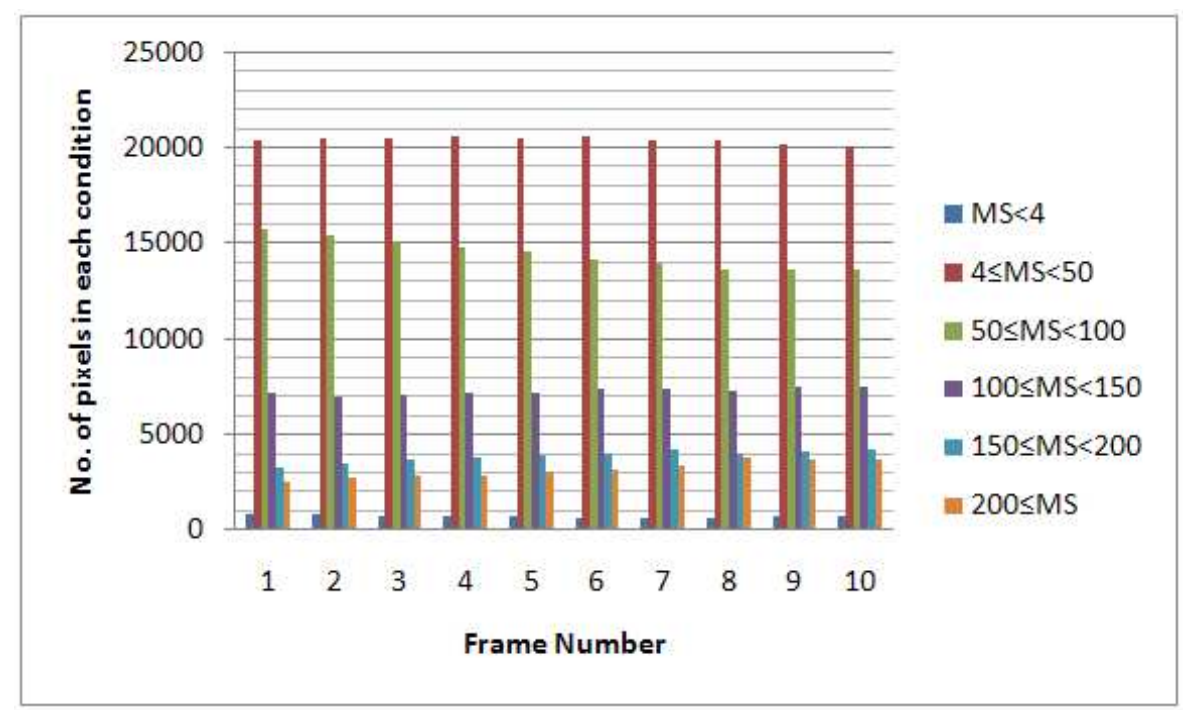

그림 7. Bus 영상의 필드별 $\mathrm{MS}$ 값의 히스토그램

Fig 7. Histogram of MS values in each field of Bus image

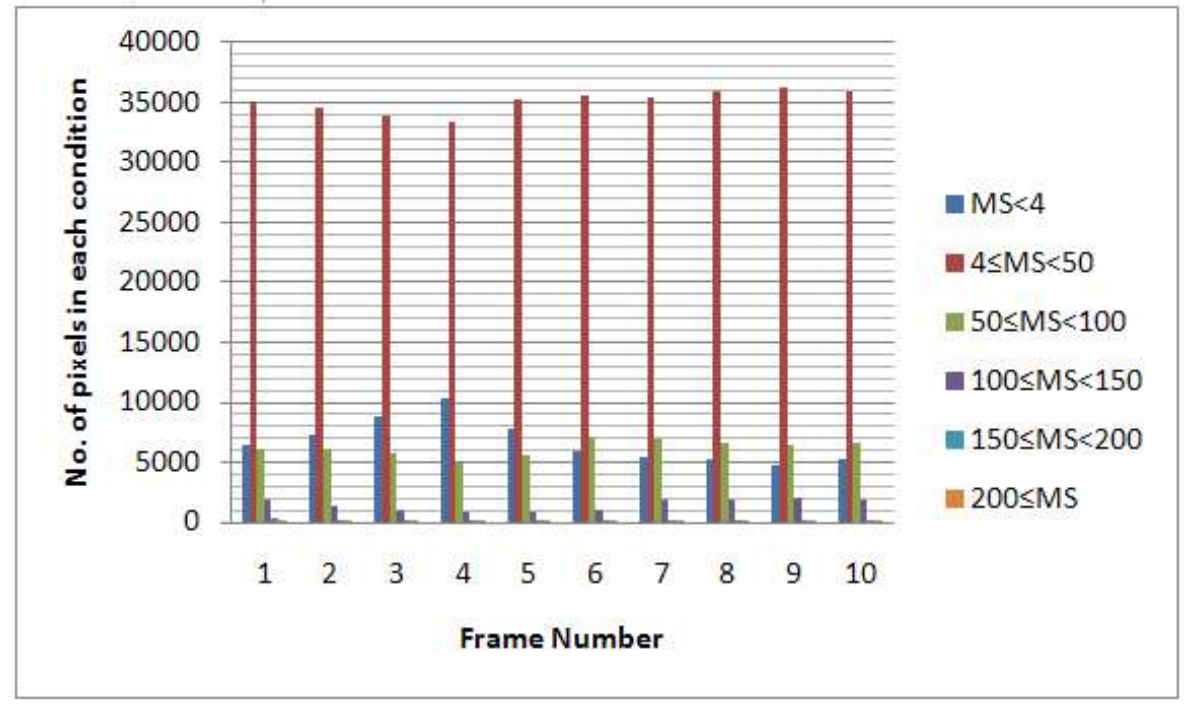

그림 8. Foreman 영상의 필드별 MS값의 히스토그램

Fig 8. Histogram of MS values in each field of Foreman image

Silent으로 평균 MS값은 16.9이다. Foreman, Hall, Highway, Tempete, Waterfall, Coastguard, Bridge_Close, Bridge_Far, Paris, Container를 포함한 나머지 영상(Group $\mathrm{B}$ )들은 부분적인 움직임이 있는 영상들로 평균 $\mathrm{MS}$ 값은 46.8 이다. 위에서 실험 영상으로 사용한 19가지 영상에서
나온 평균 $\mathrm{MS}$ 값을 가지고 영상의 유형을 3 가지로 나눌 수 있었다. 3 가지 유형으로 상위, 하위 임계값을 5 단계씩 변화 시키며 실험을 하여 가장 좋은 결과가 나오는 임계값을 정 하여 실험을 하였다. 


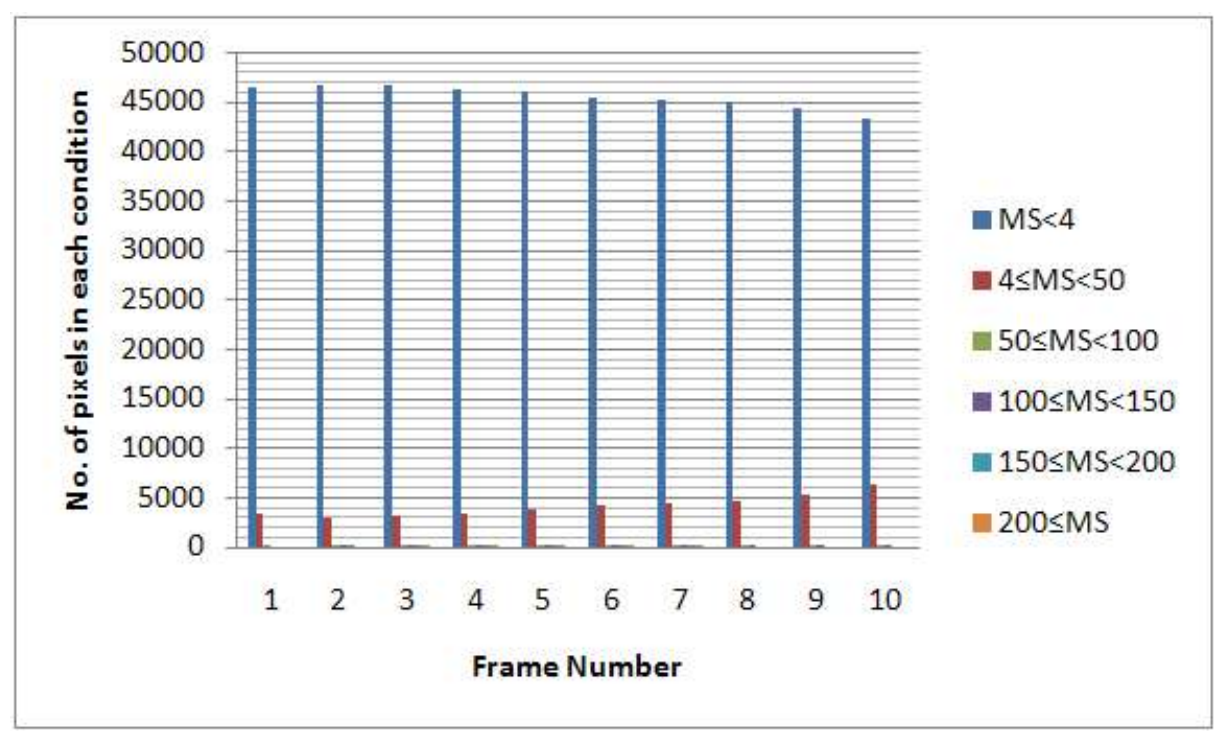

그림 9. Akiyo 영상의 필드별 MS값의 히스토그램

Fig 9. Histogram of MS values in each field of Akiyo image

표 1은 다양한 동영상에 대하여 ELA, E-ELA, M-ELA, $\mathrm{DOI}$, 그리고 제안된 방법에 따른 PSNR(peak signal to noise ratio)을 제시하였다. 기존의 디인터레이싱 방법보다 평균 $1.58 \sim 2.01 \mathrm{~dB}$ 정도 개선된 것을 볼 수 있다. 영상의
유형에 따라 움직임이 전체에 있는 영상(A Group), 움직임 이 부분적으로 큰 영상(Group B), 움직임이 적은 영상 (Group C) 모두 객관적으로 우수한 성능을 보임을 알 수 있었다. Group B 에서 Foreman의 경우는 움직임의 변동이

표 1. 객관적 회질 평가를 위한 PSNR값 측정

Table 1. Measurement in PSNR value for object quality assessment

\begin{tabular}{|c|c|c|c|c|c|c|c|}
\hline No & Group & 영상 & ELA & E-ELA & M-ELA & DOI & Proposed \\
\hline 1 & \multirow{5}{*}{$A$} & Flower & 17.76 & 17.74 & 17.68 & 17.7 & 17.79 \\
\hline 2 & & Football & 20.77 & 20.77 & 20.76 & 20.75 & 20.87 \\
\hline 3 & & Mobile & 19.64 & 19.89 & 19.94 & 20.11 & 20.18 \\
\hline 4 & & Bus & 16.79 & 16.77 & 16.74 & 16.76 & 16.89 \\
\hline 5 & & Stefan & 19.32 & 19.35 & 19.37 & 19.46 & 19.8 \\
\hline 6 & \multirow{10}{*}{ B } & Foreman & 26.93 & 26.94 & 26.93 & 26.89 & 26.72 \\
\hline 7 & & Hall & 27.94 & 28.14 & 28.32 & 28.61 & 31.38 \\
\hline 8 & & Highway & 30.12 & 30.11 & 30.08 & 30.75 & 30.39 \\
\hline 9 & & Tempete & 24.05 & 24.42 & 24.61 & 24.76 & 25.32 \\
\hline 10 & & Waterfall & 30.73 & 31.04 & 31.35 & 32 & 33.21 \\
\hline 11 & & Coastguard & 23.03 & 23.03 & 23.01 & 23.03 & 23.4 \\
\hline 12 & & Bridge-Close & 29.13 & 29.29 & 29.35 & 29.45 & 34.49 \\
\hline 13 & & Bridge-Far & 33.9 & 34 & 34 & 33.87 & 37.87 \\
\hline 14 & & Paris & 23.31 & 23.52 & 23.7 & 24.04 & 26.19 \\
\hline 15 & & Container & 27.57 & 27.79 & 28.01 & 28.32 & 33.76 \\
\hline 16 & \multirow{4}{*}{ C } & Akiyo & 35.09 & 35.93 & 36.23 & 36.51 & 37.9 \\
\hline 17 & & Mother & 34.43 & 34.58 & 34.69 & 34.77 & 36.44 \\
\hline 18 & & News & 29.01 & 29.46 & 29.73 & 29.99 & 33.42 \\
\hline 19 & & Silent & 28.93 & 29.04 & 29.11 & 29.19 & 30.72 \\
\hline \multicolumn{3}{|c|}{ Average } & 26.23 & 26.41 & 26.50 & 26.68 & 28.24 \\
\hline
\end{tabular}


표 2. 실험 영상의 CPU Time 결과

Table 2. Results of CPU time for test sequences (ms/frame)

\begin{tabular}{|c|c|c|c|c|c|c|}
\hline No & 영상 & ELA & E-ELA & M-ELA & DOI & Proposed \\
\hline 1 & Flower & 15.65 & 16.21 & 16.8 & 1059.62 & 879.11 \\
\hline 2 & Football & 15.55 & 15.81 & 15.23 & 703.13 & 716.85 \\
\hline 3 & Mobile & 15.63 & 16.8 & 17.01 & 1313.68 & 1075.23 \\
\hline 4 & Bus & 15.65 & 16.6 & 15.81 & 1206.23 & 1031.76 \\
\hline 5 & Stefan & 15.62 & 16.65 & 15.63 & 1217.43 & 1023.78 \\
\hline 6 & Foreman & 15.61 & 16.18 & 16.21 & 566.82 & 608.72 \\
\hline 7 & Hall & 15.62 & 16.96 & 16.36 & 476.48 & 491.22 \\
\hline 8 & Highway & 15.68 & 16.27 & 15.82 & 258.22 & 369.36 \\
\hline 9 & Tempete & 15.65 & 16.81 & 16.4 & 1227.16 & 1034.15 \\
\hline 10 & Waterfall & 15.63 & 17.38 & 16.38 & 1252.18 & 1178.52 \\
\hline 11 & Coastguard & 15.57 & 15.81 & 15.63 & 1519.96 & 1336.92 \\
\hline 12 & Bridge-Close & 15.65 & 16.57 & 15.8 & 773.83 & 786.51 \\
\hline 13 & Bridge-Far & 15.63 & 17.37 & 16.96 & 306.22 & 413.93 \\
\hline 14 & Paris & 15.62 & 17.38 & 16.75 & 905.31 & 776.8 \\
\hline 15 & Container & 15.67 & 16.55 & 16.21 & 817.36 & 789.3 \\
\hline 16 & Akiyo & 15.51 & 16.96 & 16.41 & 334.62 & 325.16 \\
\hline 17 & Mother & 15.63 & 17.37 & 15.96 & 408.07 & 428.55 \\
\hline 18 & News & 15.61 & 17.17 & 16.43 & 547.87 & 475.38 \\
\hline 19 & Silent & 15.61 & 17.4 & 15.61 & 775.75 & 80.53 \\
\hline & Average & 15.62 & 16.75 & 16.17 & 824.73 & 765.46 \\
\hline
\end{tabular}

큰 영상으로 영상 Frame마다 다른 임계값이 자동으로 적용 된 영상이다. 객관적인 부분에서는 다른 방법 대비 안 좋게 나왔지만 주관적 평가에서는 기존의 방법보다 우수한 성능
을 확인하였다.

표 2는 다양한 동영상에 대하여 ELA, E-ELA, M-ELA, $\mathrm{DOI}$, 그리고 제안된 방법에 따른 $\mathrm{CPU}$ Time을 측정하였다.

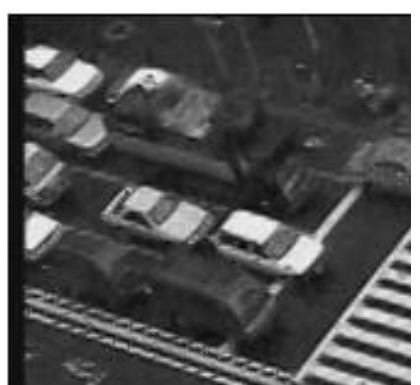

ELA

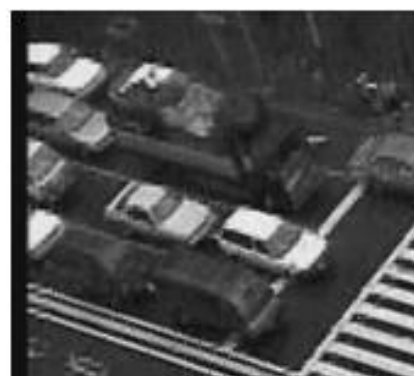

DOI

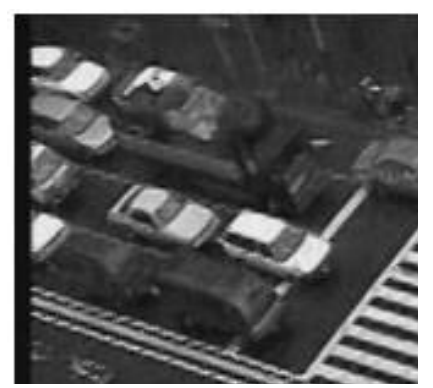

E-ELA

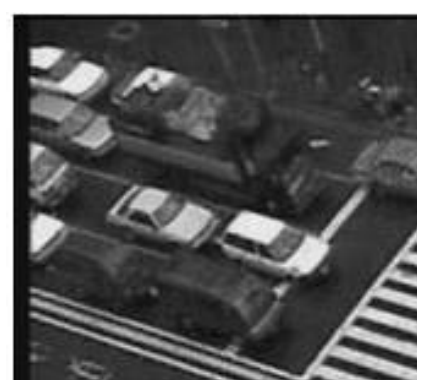

Proposed

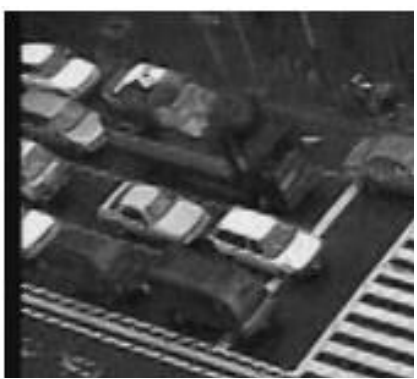

M-ELA

그림10. Cross walk 일부 확대영상

Fig 10. Zoomed results of a part of Cross walk image 
가장 연산량이 많은 방법은 DOI 방법으로 나타났다. DOI 방법은 넓은 검색 범위로 인하여 많은 연산을 하는 방법이 다. 제안하는 방법이 DOI 방법 대비 평균 $93 \%$ 의 효율을 보이는 것을 확인 할 수 있었다. 반면 ELA, E-ELA, MELA 계열의 방법보다는 연산량이 높게 나오는 것을 볼 수 있었다. ELA계열은 단순한 방법이나 수평 에지에 취약하 므로 단순 계산량 비교로 평가하기에는 적합 하지 않다.

그림 10 의 Cross walk 영상은 교차로 중앙선 부분이 낮 은 각도에 ELA, E-ELA, M-ELA방법 모두 약점을 보이고 있다. 낮은 각도의 보간에서는 ELA계열의 방법 모두 잘못 된 예측을 하여 보간되는 것을 알 수 있었다. 반면 DOI 방 법은 낮은 각도의 에지에 우수한 성능을 확인하였으나 넓 은 검색 범위 때문에 가장자리는 선 평균 하는 단점이 있어 가장자리 부분에서 약점을 보이고 있다. 반면 제안하는 방 법이 가장 우수한 화질을 확인하였다. 그림 11의 Foreman 영상의 경우 영상의 변화가 심한 영상 중 하나로 PSNR에 서는 가장 안 좋은 값이 나왔다. 이 영상의 경우는 큰 영역 을 차지하는 얼굴이 전체적으로 흔들려 공간적 디인터레이
싱을 수행하게 된다. 하지만 제안된 방법에 의하면 배경 부 분은 별도로 시간적 디인터레이싱을 적용하므로 낮은 각이 강하게 나오는 배경에서는 기존의 방법에 비해 우수한 것 을 확인하였다.

\section{V. 결 론}

본 논문에서는 비월 주사 영상을 순차 주사 영상으로 변 환하기 위한 디인터레이싱 방법을 제안한다. 영상의 유형 에 따라 움직임이 많은 영상, 움직임이 부분적으로 많은 영 상, 움직임이 적은 영상으로 구분하여 영상의 유형에 따라 임계값을 다르게 두어 디인터레이싱을 수행하였다. 에지의 정확한 판단을 위하여 소벨 연산을 사용하여 정확한 에지 의 방향을 찾은 다음 45도 보다 큰 각도의 방향일 경우에는 수직 성분의 에지가 강한 영상에 강점을 보이는 M-ELA 방 법으로 보간하고, 45 도 보다 작은 각도의 방향일 경우에는 M-DOI 방법을 사용하여 향상된 보간이 이루어지게 하였

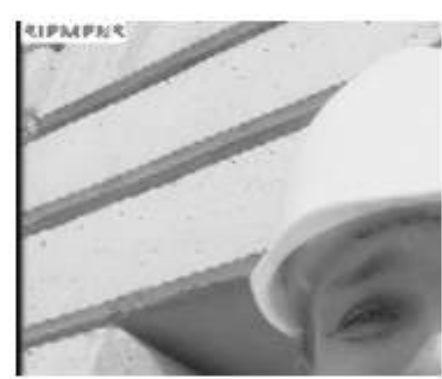

ELA

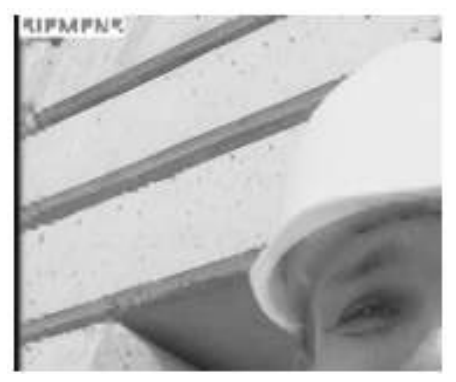

DOI

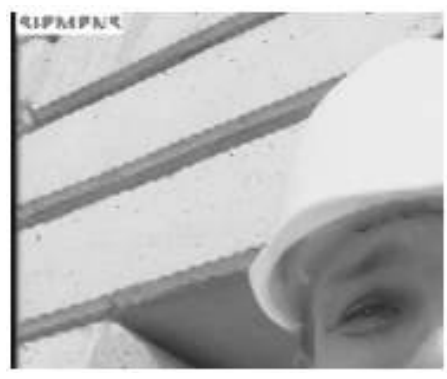

E-ELA

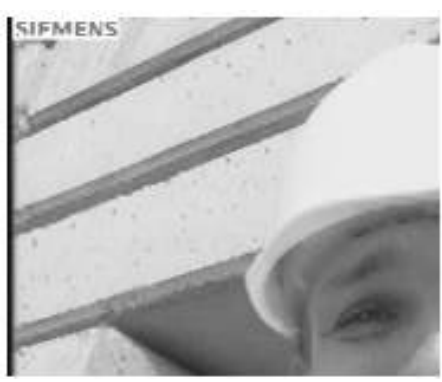

Proposed

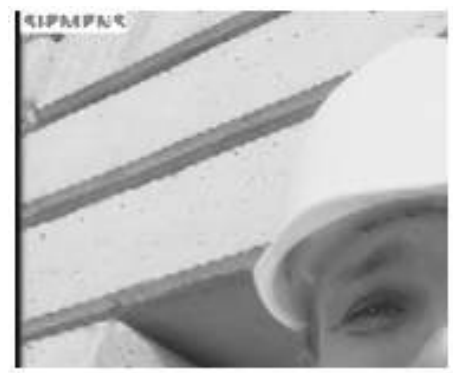

M-ELA

그림11. Foreman 일부 확대영상

Fig 11. Zoomed results of a part of Foreman image 
다. 정지 영역에서는 기존의 필드 반복 방법을 사용하였다. 영상의 콘텐츠에 따라 다양한 영상이 자동으로 임계값이 계산되어 적용되는 움직임 적응형 디인터레이싱 기법을 제 안하여 잡음의 영향을 줄이고 좀 더 정확한 움직임을 검출 할 수 있도록 하였다. 다양한 실험 영상을 통하여 모의실험 결과 제안 방법은 기존의 디인터레이싱 방법의 문제점 개 선을 하였으며 기존의 방법에 비해 우수한 성능을 보였다. 향후의 연구에서는 움직임 검출에서 상위, 하위 임계값 결정을 영상의 유형에 따라 자동적으로 조정하는 방법과 공간적 디인터레이싱 방법을 보다 개선하고 제안한 기법을 하드웨어로 최적화하여 구현을 하고자 한다.

\section{참 고 문 헌}

[1] Gerard De Haan, Erwin B.Bellers, "Deinterlacing -An Overview", Proceedings of IEEE, Vol. 86, No. 9, pp.1839-1857, Sep. 1998

[2] Brian A. Heng, "Application of deinterlacing for the enhancement of surveillance video.", Thesis(S.M.)-Massachusetts Institute of Technology, Dept. of Electrical Engineering and Computer Science, 2001.

[3] Tao Chen, Hong Ren Wu, and Zheng Hua Yu, "Efficient Deinterlacing algorithm using edge-based line average interpolation", Optical Engineering, Vol. 39, No. 8, pp. 2101-2105, Aug. 2000
[4] Hoon Yoo, Jechang Jeong, "Direction-Oriented interpolation and its application to De-interlacing" IEEE Trans. on Consumer Electronics, Vol. 48, No. 4, pp.954-962, Nov. 2002.

[5] Soonjong Jin, Wonki Kim and Jechang Jeong, "Fine Directional De-interlacing Algorithm Using Modified Sobel Operation", IEEE transaction on Consumer Electronics, Vol. 54, No. 2, pp.857-862, MAY 2008.

[6] 김원기, 진순종, 정제창, "공간적 디인터레이싱을 위한 컨텐츠 기반 적응 적 보간 기법”, 한국통신학회논문지, Vol. 32 , No. 10, pp.1000-1009 2007년 10월.

[7] 가유라, 김민환, 박인혜, 송승태, 정혜경, 이성원, “블록 기반의 움직임 적 응형 디인터레이싱 기법”, 제 21 회 신호처리합동학술대회, 서울, 광운대, 2008년 9월.

[8] 오세훈, 이여송, 안창범, 오승준, “방향성 오류 교정을 위한 투표 결정 기반 의 디인터레이싱 방법”, 한국방송공학회, 방송공학회논문지, 제 14 권 제 3 호 pp.342 356, 2009년 5월.

[9] 김민환, 이성원, “콘텐츠 기반의 움직임 적응형 디인터레이싱 기법”, 한국 방송공학회 하계학술대회, 제주, 제주그랜드호텔, P-6-7, 2010년 7월.

[10] Gwanggil Jeon, Marco Anisetti, Joohyun Lee, Valerio Bellandi, Ernesto Damiani, "Concept of Linguistic Variable-Based Fuzzy Ensemble Approach: Application to interlaced HDTV Sequences", IEEE Transactions on fuzzy system, Vol. 17, No. 16, DECEMBER, 2009.

[11] Gwanggil Jeon, Min Young Jung, Marco Anisetti, Valerio Bellandi, Ernesto Damiani, "Specification of the Geometric Regularity Model for Fuzzy If-Then Rule-Based Deinterlacing", IEEE Journal of display technology, Vol. 6, No. 6, JUNE 2010.

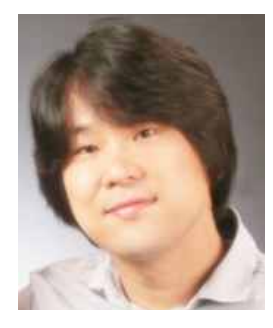

김 민 환

- 2010년 2월 : 광운대학교 컴퓨터공학과 (학사)

- 2010년 3월 현재 : 광운대학교 컴퓨터공학과 (석·박사통합과정)

- 주관심분야 : Deinterlacing, 신호처리 SoC, PMIC 
저 자 소 개

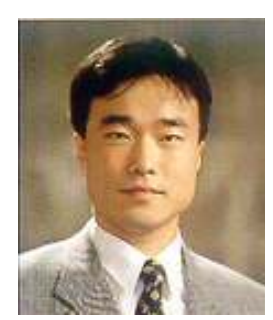

\section{이 창 우}

- 1988년 2월 : 서울대학교 제어계측공학과 (학사)

- 1990년 2월 : 서울대학교 제어계측공학과 (석사)

- 1996년 2월 : 서울대학교 제어계측공학과 (박사)

- 1996년 3월 1997년 8월 : 삼성전자 신호처리연구소 선임연구원

- 1997년 9월 현재 : 가톨릭대학교 정보통신전자공학부 교수

- 주관심분야 : 영상부호화, 영상통신

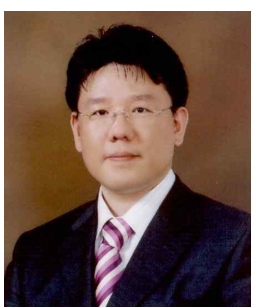

\section{이 성 원}

- 1988년 2월 : 서울대학교 제어계측공학과 (학사)

- 1990년 2월 : 서울대학교 제어계측공학과 (석사)

- 2003년 5월 : Univ. of Southern California (박사)

- 1990년 2월 2004년 2월 : 삼성전자 반도체부문 시스템 LSI 책임연구원

- 2005년 3월 현재 : 광운대학교 컴퓨터공학과 부교수

- 주관심분야 : 영상신호처리, 신호처리 SoC, 컴퓨터구조 